\title{
Ribosomal DNA transcription in prefrontal pyramidal neurons is decreased in suicide
}

\author{
Marta Krzyżanowska ${ }^{1}$ Johann Steiner ${ }^{2}$ - Dorota Pieśniak ${ }^{1} \cdot$ Karol Karnecki $^{1} \cdot$ Michał Kaliszan $^{1} \cdot$ Marek Wiergowski $^{1}$. \\ Krzysztof Rębała ${ }^{1}$. Ralf Brisch ${ }^{1} \cdot$ Katharina Braun $^{3}$ - Zbigniew Jankowski ${ }^{1}$ Monika Kosmowska ${ }^{1}$ · Joanna Chociej ${ }^{1}$. \\ Tomasz Gos ${ }^{1,2,3}$
}

Received: 3 January 2019 / Accepted: 22 February 2019 / Published online: 11 March 2019

(c) The Author(s) 2019

\begin{abstract}
Prefrontal cortical regions, which are crucial for the regulation of emotionally influenced behaviour, play most probably a dominant role in the pathogenesis of suicide. The study was carried out on paraffin-embedded brain tissue blocks containing specimens from the anterior cingulate cortex (dorsal and ventral parts), the orbitofrontal cortex, and the dorsolateral cortex obtained from 23 suicide completers (predominantly violent) with unknown psychiatric diagnosis and 25 non-suicidal controls. The transcriptional activity of ribosomal DNA (rDNA) as a surrogate marker of protein biosynthesis was evaluated separately in layers III and V pyramidal neurons in regions of interest (ROIs) mentioned above by the AgNOR silver staining method bilaterally. The overall statistical analysis revealed a decrease of AgNOR area suggestive of attenuated rDNA activity in suicide victims versus controls, particularly in male subjects. Further ROI-specific post-hoc analyses revealed decreases of the median AgNOR area in suicides compared to non-suicides in all 16 ROIs. However, this effect was only significant in the layer $\mathrm{V}$ pyramidal neurons of the right ventral anterior cingulate cortex. Our findings suggest that decreased rDNA transcription in prefrontal pyramidal neurons plays possibly an important role in suicide pathogenesis.
\end{abstract}

Keywords Postmortem $\cdot$ Suicide $\cdot$ Prefrontal cortex $\cdot$ AgNOR staining

\section{Introduction}

Disturbances of the prefrontal cortex (PFC) regions, which play a pivotal role in behavioural regulation, are implicated in a multifaceted way in suicidal behaviour (for reviews see:

The authors dedicate this work to the memory of Professor Roman Hauser.

Electronic supplementary material The online version of this article (https://doi.org/10.1007/s00406-019-00996-0) contains supplementary material, which is available to authorized users.

Tomasz Gos

gost@gumed.edu.pl

1 Department of Forensic Medicine, Medical University of Gdańsk, ul. Dębowa 23, 80-204 Gdańsk, Poland

2 Department of Psychiatry, Otto-von-Guericke-University, Magdeburg, Germany

3 Department of Zoology/Developmental Neurobiology, Institute of Biology, Otto-von-Guericke-University, Magdeburg, Germany
$[1,2])$. This behaviour has been proposed to be an independent mental disorder in the fifth edition of the Diagnostic and Statistical Manual of Mental Disorders-DSM V [3] in accordance with numerous neurobiological research data (for reviews see: [1,2]). The distinctness of suicide in mental disorders has been also suggested by our own neuropathological research [4-6] (for a review of our previous studies see: [7]).

Nucleolar organising regions (NORs) are genetic loci on chromosomes that are composed of ribosomal DNA (rDNA) and proteins, some of which are argyrophilic. In human interphase cells, silver-stained NORs (AgNORs) clustered together in the nucleolus represent the site of transcriptionally active NORs and ribosomal RNA synthesis, which constitutes approximately half of the entire transcriptional activity in the cell. In the AgNOR staining evaluated by light microscopy, AgNORs are indistinguishable from each other and form the AgNOR area. It is located in the nucleolar area but smaller than this area (compared, for instance, with haematoxylin-eosin and Nissl stainings [8]). As a surrogate marker of protein biosynthesis and an important sensor of 
cellular stress of different nature, the transcriptional activity of rDNA can be assessed by measuring AgNOR parameters. These are: AgNOR area (representing the nucleolus), AgNOR number (i.e. the number of AgNOR areas within one nucleus) and AgNOR ratio defined as the quotient of total AgNOR area in the nucleus and nuclear area [9-22] (for reviews see: [23, 24]).

A key role of rDNA transcriptional activity in neuronal plasticity has been proven in neuronal culture [25-27] and molecular studies have revealed that this activity is decreased in the hippocampus of suicidal patients [28]. Our previous AgNOR studies of the PFC [13, 15] and other brain structures $[5-7,10,14,17]$ have suggested decrease of neuronal rDNA transcription in suicide, which is consistent with molecular results [28]. In addition, our recent AgNOR research on dorsal raphe nucleus (DRN) neurons has implied a decreased rDNA transcription as a diagnosis-overreaching phenomenon specific for suicide [5, 6], which may be useful for the forensic differentiation between suicidal and nonsuicidal death [6]. Previous neuropathological research by us and other researchers has also suggested an increased microglial reaction in the PFC of suicidal patients as a phenomenon independent of psychiatric diagnosis [29, 30]. This finding may be related to decreased rDNA transcription in pyramidal neurons via the induction of oxidative stress [31, 32].

Therefore, in the present study we hypothesized a decreased rDNA transcriptional activity in prefrontal pyramidal neurons in suicide completers regardless of their underlying psychiatric diagnosis (i.e. independent of psychiatric comorbidity) and tested this hypothesis by the application of AgNOR staining in forensic postmortem material. We aimed at both basic research on the neurobiology of suicide and the evaluation of a possible usefulness of this method in forensic diagnostics for the differentiation between suicidal and non-suicidal death.

\section{Materials and methods}

\section{Human brain tissue}

Prefrontal parts of both hemispheres of sudden death controls and suicide victims with unknown data both on psychiatric comorbidity and on possible psychotropic medication preceding death (typical for most of suicide cases autopsied in our Department of Forensic Medicine) were obtained during routine forensic autopsies in accordance with existing EU law regulations. The study has been approved by the local ethics committee of the Medical University of Gdańsk in accordance with the ethical standards laid down in the Declaration of Helsinki, version 1989.
Detailed diagnostic, demographic and toxicological data are presented in Supplementary Table 1. Violent suicide methods prevailed in the suicide cohort (15 out of 23), which is representative for our autopsy material. All brains were free of neuropathology suggestive of vascular, traumatic, inflammatory, neoplastic and neurodegenerative processes. A toxicology screen on blood and urine for ethanol was performed at each autopsy. The majority of investigated cases (19 suicide victims and 18 controls, see Supplementary Table 1) revealed a blood alcohol concentration (BAC) below the limit of quantification (LOQ), i.e. $<0.2 \mathrm{~g} / \mathrm{l}$ according to internationally accepted analytical guidelines. Other substances of abuse, antidepressant and antipsychotic drugs, as well as their metabolites were investigated when an intoxication was suggested by the scene inspection and/or other available information sources prior to the autopsy, i.e. in eight cases. These cases constituted the non-violent suicide subgroup (see Supplementary Table 1).

Prefrontal parts of the brains were separated from both hemispheres by coronal sections at the level of temporal poles and fixed in toto in 10\% phosphate-buffered formaldehyde for 1 week. After being fixated, tissue blocks were isolated closely to the section plane from the following prefrontal regions: dorsolateral prefrontal cortex (DLPFC), anterior cingulate cortex (dorsal (ACd) and ventral (ACv) parts) and orbitofrontal cortex (OFC) (see Fig. 1a), and embedded in paraffin. Subsequently, serial 5- $\mu \mathrm{m}$ thick transverse sections in frontal plane were cut along these tissue blocks. Every 200th section was mounted and stained for AgNOR.

\section{AgNOR staining}

Silver staining was carried out as previously described [10]. Briefly, paraffin sections were dewaxed and rehydrated through graded alcohols. The silver stain was freshly prepared by mixing $2 \%$ gelatin (dissolved in $1 \%$ aqueous formic acid) with $50 \%$ aqueous silver nitrate solution at a 1:2 ratio. The sections were incubated with this mixture in a dark moist chamber at room temperature for $45 \mathrm{~min}$ and subsequently washed with deionised water. Following this protocol, the AgNOR area-containing AgNORs (that are clustered, undistinguishable from each other) and representing the nucleolus-appears as an intranuclear, clearly delineated black or dark brown small spot and the nuclear border is clearly visible in the majority of large pyramidal neurons (Fig. 1b). Glia cells were distinguished from neurons according to established cytomorphological criteria [34].

\section{Quantification}

In each of 16 investigated regions of interest (ROIs), i.e. cortical layers III and V in each of 4 prefrontal regions bilaterally, AgNOR parameters were determined in 40 


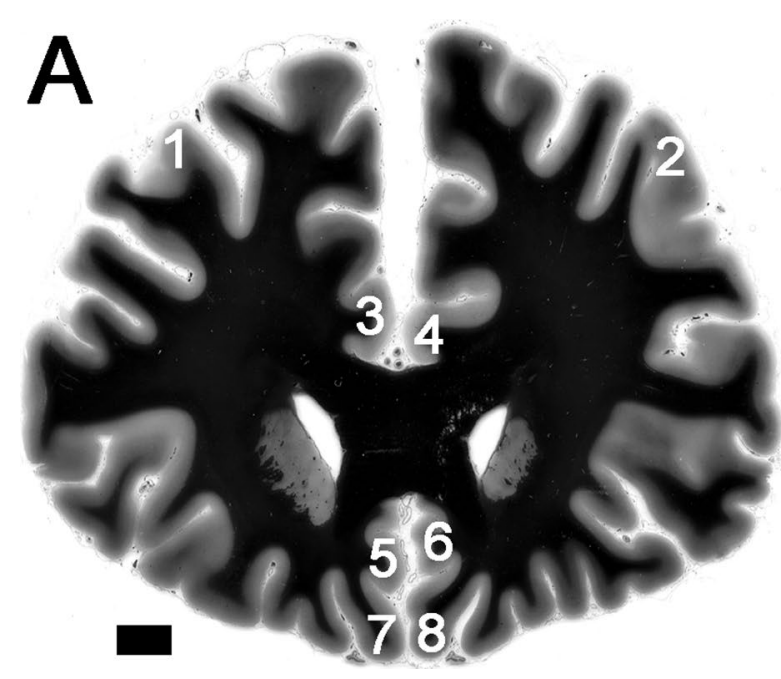

Fig. 1 a Regions of interest in the prefrontal cortex are outlined bilaterally (1-dorsolateral right, 2 -dorsolateral left; 3 -anterior cingulate dorsal right, 4-anterior cingulate dorsal left; 5-anterior cingulate ventral right, 6-anterior cingulate ventral left; 7-orbitofrontal right, 8 -orbitofrontal left) at low magnification picture of the Nissl-

neurons with clearly visible borders of the nucleus and AgNOR areas. These neurons were selected throughout available AgNOR stained sections, i.e. in five sections for each tissue block ( 40 sections for each case), on the average. Thus, the AgNOR parameters of 640 pyramidal neurons were investigated in each case. The number of investigated neurons was established arbitrarily in accordance with diagnostic and research studies employing the AgNOR method. This method does not require an estimation of the number of cells and/or nuclei [10]. The neurons were sampled using a $400 \times$ magnification. The AgNOR areas (composed of clustered AgNORs and representing the nucleoli), their number and the nuclear area within a single sampled neuron were determined using a light microscope attached to a computer image analysis system (cellSens ${ }^{\circledR}$, Olympus, Japan). In this system, each of the neurons sampled by $400 \times$ magnification was visualised digitally, focused, and the sharpest and longest profiles of the nucleus and AgNOR areas were traced by the mouse cursor on the screen. As a result, the numerical values of AgNOR and nuclear areas and the numbers of AgNOR areas were calculated automatically. Subsequently, the AgNOR ratio (relative AgNOR area) was derived by dividing the total AgNOR area by the nuclear area, taking into account all the AgNOR areas present per neuronal nucleus. This procedure was performed separately for each of the sampled neurons. The sampled measures were averaged to derive a single set of values for each ROI in each of investigated cases (i.e. 16 values in each case).

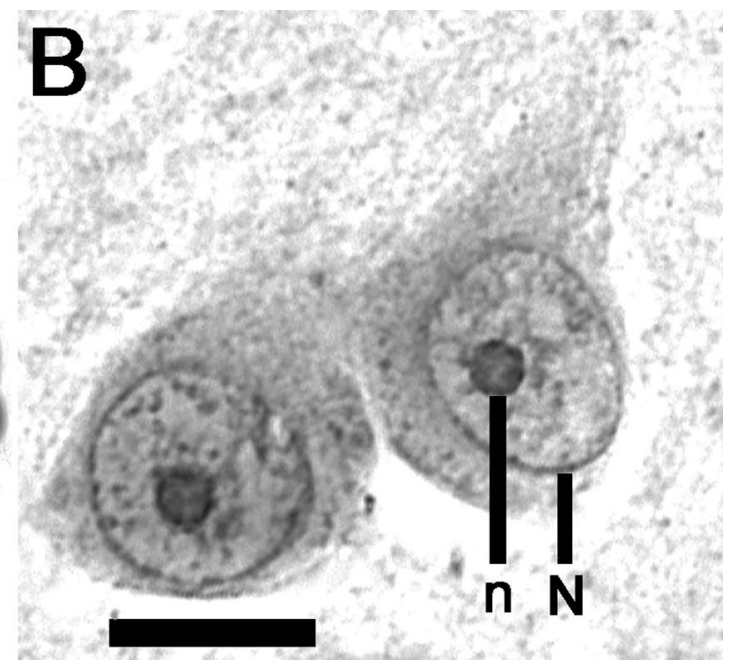

myelin-stained coronal section at the level where investigations were carried out (scale bar $10 \mathrm{~mm}$; the staining method is described in [33]). b After AgNOR staining the borders of the nucleus (N) and the AgNOR area (representing the nucleolus) (n) areclearly visible within prefrontal pyramidal neurons (scale bar $10 \mu \mathrm{m}$ )

\section{Data analysis}

Statistical analyses were performed with the data analysis software system STATISTICA version 10 (StatSoft ${ }^{\circledR}$, Inc. 2011, http://www.statsoft.com). As normal distribution was not given for all analysed AgNOR parameters (i.e. significant values of Kolmogorov-Smirnov tests were obtained), non-parametric statistical procedures were used in hierarchic mode.

First, STATISTICA generalized linear/nonlinear models (GLZ) module containing general custom designs (GCD) procedure was applied as an omnibus method to analyse associations between dependent variables (i.e. AgNOR parameters) and independent categorical variables (i.e. suicidal/control groups, PFC region, cortical layer, and sex as the categorical confounding variable). The results of GCD analysis were reported automatically including the Wald statistic value, degrees of freedom and the respective $P$ value. This initial GCD analysis revealed that only AgNOR area was related to suicide, which was an effect associated with sex. Therefore, further analyses were performed only for AgNOR area.

Age, postmortem interval, brain weight and BAC (values below LOQ were accounted null values in statistical analysis) were considered as numerical confounding variables. Therefore, the subsequent GCD procedure was applied in each of ROIs to analyse associations between AgNOR area and these variables. Supplementary to GCD analyses in ROIs, Spearman correlation coefficients were 
calculated to determine the impact of numerical variables which might confound AgNOR area.

Subsequently to GCD analyses, unadjusted two-way post-hoc comparisons with Mann-Whitney $U$ test and the $\chi^{2}$ test were used to detect the possible differences between the study groups with respect to the variables mentioned above (i.e. AgNOR area and confounders). $U$ test was also used to detect the possible difference in AgNOR area between violent $(n=15)$ and non-violent suicides (i.e. self-poisoning cases in our cohort, $n=8$ ). All statistical tests were two-tailed. Generally, $P$ values of 0.05 were accepted as statistically significant.

Kruskal-Wallis analysis of the variance of ranks ( $H$ test) with subsequent post-hoc $U$ tests were performed for the evaluation of differences in the AgNOR area related to sex between suicides and controls, which was suggested by the GCD analysis; in this procedure $U$ test $P$ values were adjusted to multiple comparisons according to the Bonferroni correction.

STATISTICA automatic neuronal networks (SANN) module containing receiver operating characteristic (ROC) procedure was applied for the evaluation of the discriminative value of the AgNOR method, i.e. its accuracy (represented by the area under ROC curve), sensitivity and specificity for the differentiation between suicidal and non-suicidal death.

\section{Results}

\section{Qualitative analysis of the AgNOR staining}

After AgNOR staining of the PFC pyramidal neurons, borders of the AgNOR area (containing AgNORs that were clustered together and indistinguishable from each other) were clearly visible (Fig. 1b) in line with the staining patterns in these neurons presented previously $[13,15]$. Most of the neurons contained one AgNOR area (representing the nucleolus in this staining method). Two or more AgNOR areas were observed very rarely, which explains why the AgNOR number was near 1.

\section{Quantitative analysis of the AgNOR staining}

The differences in AgNOR parameters were beyond qualitative evaluation and they could only be captured by means of quantitative measurements.

Cumulative analyses of results from all investigated 16 ROIs (i.e. from cortical layers III and V in 4 evaluated PFC regions bilaterally, 384 suicidal and 400 control values for each of AgNOR parameters) by GCD procedure revealed the strong association of forensic diagnosis (i.e. suicide versus non-suicide) with the AgNOR area (Wald statistic $=33.87$, $d f=1, P=0.00000000589$; median values $6.91 \mu^{2}$ and 7.21 $\mu \mathrm{m}^{2}$ for suicides and non-suicidal controls, respectively, see Table 1). This effect was not associated with the brain hemisphere, investigated PFC region or cortical layer. Instead,

Table 1 Summarised statistical data regarding the comparison between suicide victims $(n=23)$ and controls $(n=25)$

\begin{tabular}{|c|c|c|c|c|c|c|c|c|}
\hline $\begin{array}{l}\text { Intergroup } \\
\text { comparisons }\end{array}$ & Sex & Age (year) & PMI (h) & BAC $(\mathrm{g} / \mathrm{l})$ & $\begin{array}{l}\text { AgNOR area } \\
\text { cum all }\end{array}$ & $\begin{array}{l}\text { AgNOR area cum } \\
\text { males }\end{array}$ & $\begin{array}{l}\text { AgNOR area } \\
\text { cum females }\end{array}$ & $\begin{array}{l}\mathrm{AgNOR} \text { area } \\
\text { right } \mathrm{ACv} \text { layer } \\
\mathrm{V}\end{array}$ \\
\hline \multicolumn{9}{|l|}{ Suicide victims } \\
\hline $\begin{array}{l}\text { Ratio/ } \\
\text { median } \\
(q 1, q 3)\end{array}$ & $17 \mathrm{~m} / 6 \mathrm{f}$ & $\begin{array}{l}41.5(28.5, \\
57.5)\end{array}$ & $24(24,39)$ & $\begin{array}{l}0.00(0.00 \\
0.00)\end{array}$ & $\begin{array}{l}6.914(6.228 \\
7.781)\end{array}$ & $\begin{array}{l}6.698(6.040 \\
7.448)\end{array}$ & $\begin{array}{l}7.558(6.895 \\
8.997)\end{array}$ & $\begin{array}{l}6.845(6.148 \\
7.515)\end{array}$ \\
\hline \multicolumn{9}{|l|}{ Controls } \\
\hline $\begin{array}{l}\text { Ratio/ } \\
\text { median } \\
(q 1, q 3)\end{array}$ & $21 \mathrm{~m} / 4 \mathrm{f}$ & $57(28,61)$ & $24(15,30)$ & $\begin{array}{l}0.00(0.00 \\
0.00)\end{array}$ & $\begin{array}{l}7.212(6.452 \\
8.418)\end{array}$ & $\begin{array}{l}7.170(6.406, \\
8.333)\end{array}$ & $\begin{array}{l}7.744(6.849, \\
8.992)\end{array}$ & $\begin{array}{l}7.734(7.064, \\
8.368)\end{array}$ \\
\hline \multicolumn{9}{|l|}{ Statistics } \\
\hline Test & $\chi^{2}$-test & $U$ & $U$ & $U$ & $G C D$ & $G C D$ & $G C D$ & $U$ \\
\hline $\begin{array}{l}\text { Characteris- } \\
\text { tic value }\end{array}$ & $\chi^{2}=0.610$ & $Z=0.890$ & $Z=-0.790$ & $Z=0.420$ & $\begin{array}{r}\text { Wald statis- } \\
\text { tic }=33.87\end{array}$ & $\begin{array}{l}\text { Wald statis- } \\
\text { tic }=43.31\end{array}$ & $\begin{array}{l}\text { Wald statis- } \\
\quad \text { tic }=0.03\end{array}$ & $Z=2.270$ \\
\hline$P$ value & 0.435 & 0.373 & 0.429 & 0.675 & 0.00000000589 & 0.0000000000468 & 0.866 & 0.0232 \\
\hline
\end{tabular}

$P M I$-postmortem interval, BAC - blood alcohol concentration, cum —cumulated results from layers III and V in all analysed regions of interest (ROIs), $A C v$-anterior cingulate cortex, ventral part, $f$-female, $m$-male, $q 1$ and $q 3$-quartile 1 and 3; $G C D$-general customs design procedure (in generalized linear/nonlinear models of data analysis software system STATISTICA). (See Supplementary Table 1 for the detailed values of confounding variables and AgNOR parameters in the right ACv layer V, i.e. the only ROI where the significant difference in AgNOR area in pyramidal neurons was found between compared groups.) 
it was closely associated with sex (Wald statistic $=37.21$, $d f=1, P=0.0000000107)$, i.e. mainly driven by male subjects (see next paragraph). Other AgNOR parameters were not associated with suicide/non-suicide dichotomy (insignificant Wald statistic values) and, therefore, excluded from further analyses. As revealed by the ROC curve for cumulated AgNOR area values, the method accuracy (represented by the area under ROC curve, AUC) was $58 \%$; its sensitivity according to suicide detection was $27 \%$, whereas the specificity of suicide exclusion (i.e. the detection of non-suicidal case) was $82 \%$.

In accordance with initial GCD analysis, further ROI-specific analyses by post-hoc $U$ tests revealed decreases of the median AgNOR area in suicides compared to non-suicides in all 16 ROIs. However, this effect was only significant in the right $\mathrm{ACv}$ pyramidal cells layer $\mathrm{V}$ (see Table 1). No significant difference of AgNOR area existed between violent and non-violent suicide victims in both the cumulative analysis of the data and in the ROI-specific analyses (nonsignificant $U$ test $P$ values).

\section{Confounders}

The suicidal versus control group were matched regarding sex (non-significant $\chi^{2}$ test $P$ value, see Table 1). No significant intra-group differences between sexes were found in the AgNOR area in the right $\mathrm{ACv}$ pyramidal cells layer $\mathrm{V}$ (non-significant $U$ test $P$ values) despite higher median values presented by females. However, according to the associated effect of forensic diagnosis and sex suggested by the initial GCD procedure, only males revealed significant difference between suicides and controls in this ROI ( $U$ test $P=0.0256$; for a comparison see Table 1). On the other hand, significant intra-group differences between sexes were found in the cumulative analysis of AgNOR area values from all ROIs (corrected $U$ test $P$ values 0.0048 in control and 0.00000000013 in suicidal group; females presented higher values). GCD cumulative analyses calculated separately for both sexes revealed more significant difference in this parameter between suicides and controls in males compared to the analysis of all cases, whereas no significant effect was observed in females (see Table 1). Therefore, the observed phenomenon was specific for males. Nevertheless, ROC values for males (AUC $62 \%$, sensivity $28 \%$, and specifity $82 \%$ ) were similar to those obtained for the entire cohort.

Age, PMI and BAC revealed no significant differences between suicides and controls (non-significant $U$ test $P$ values, see Table 1), similarly as the brain weight. ROIspecific analyses by the GCD procedure revealed no associations between these numerical confounders and AgNOR area (non-significant Wald statistic $P$ values) in suicides and controls in any of investigated ROIs. Correspondingly, no relevant correlations were found between numerical confounders and AgNOR area in any ROI in both groups (non-significant Spearman correlation $P$ values and/or irrelevant $r$ values). Therefore, the results of AgNOR area analysis were not confounded by these variables.

\section{Discussion}

Our study revealed the decreased AgNOR area suggestive of attenuated rDNA transcription in prefrontal pyramidal neurons in suicide victims versus controls. Interestingly, the observed abnormality was specific for male suicides. However, the interpretation of this finding is not unequivocal. On the one hand, this effect could be related to sex-specific differences in chronically disturbed neuronal plasticity, according to reports on animal models (for a review see: [35]) and emerging human molecular studies [36] of mental disorders. On the other hand, it could be related to the higher number of males in both suicidal (17 out of 23) and control (21 out of 25) cohorts of our study. This issue could be resolved by further research on cohorts with more numerous female subjects.

The observed AgNOR area decrease was not influenced by other potentially confounding variables, among them postmortem interval. The significance was accentuated in the cumulative evaluation of all analysed ROIs independently on the hemisphere, region, and layer (i.e. layer III or $\mathrm{V}$ ). This phenomenon could be related to characteristics of PFC regions, which cooperate reciprocally in functional network [37]. However, despite the fact that the AgNOR area was decreased in suicides in all ROIs, the right $\mathrm{ACv}$ layer $\mathrm{V}$ was the only ROI where the significant difference between suicides and controls was found in separate post-hoc analyses. This effect could be related to the outstanding role played by the ventral $\mathrm{AC}$ in the regulation of emotionally influenced behaviour [38], which is profoundly disturbed in processes associated with suicide [13,39].

The results are in line with our previously published findings, which suggested a decreased rDNA transcription in PFC pyramidal neurons specific for depressed suicide completers compared to non-suicidal patients from both major depressive disorder and bipolar disorder diagnostic groups of affective disorders [13, 15]. Therefore, both our previous and present results may suggest decreased rDNA transcription in prefrontal pyramidal neurons in suicide regardless of psychiatric comorbidity. Despite of the statistical significance of our results, the AgNOR area values overlapped between the suicide and non-suicide cohorts. Consequently, the method accuracy (AUC $=56 \%$ ) does not suggest usefulness for the forensic differentiation between suicidal and non-suicidal death [40] in opposite to our previous study of the DRN (AUC $=89 \%)[6]$. 
A multitude of factors influence rDNA transcription, taking into account that the expression of hundreds of genes is involved in the regulation of this fundamental molecular process [41]. The bottleneck of these factors is the mammalian target to rapamycin (mTOR) intracellular signaling pathway, which plays the most important regulatory role in rDNA transcription [42]. Many molecular signatures of suicide are involved directly or indirectly in the action on this pathway. An outstanding example is the abnormality of glucocorticoid receptor (GR), a key component of the disturbed stress axis, which is decreased in the PFC in suicide (for a review see [43]). The decreased gene expression of spindle and kinetochore associated complex subunit 2 (SKA2) involved in the transport of GR from the neuronal cytoplasm to the nucleus may significantly contribute to this dysfunction [44]. Moreover, GR is negatively influenced by polyamines [45], which are multipotent regulatory molecules increased in suicidal PFC [46]. The dysfunction of GR produced by cumulative factors may in turn lead to the disturbed mTOR function in neurons [47] with a subsequent decrease in rDNA transcription.

Disturbed glutamatergic transmission in the PFC of suicide victims as suggested by previous postmortem studies [48-50] may also lead to mTOR hypoactivity in pyramidal neurons [51]. The blockade of $N$-methyl-D-aspartate (NMDA) glutamate receptors on prefrontal GABAergic interneurons with subsequent disinhibition of glutamatergic transmission, brain-derived neurotrophic factor (BDNF) gene expression and mTOR activity in pyramidal neurons seems to be the most important molecular effect in the rapid suicide-preventive action of ketamine [51].

Our previous research suggested GABAergic hyperactivity in prefrontal regions in depressed suicides [52], which may lead to the decreased rDNA transcription in prefrontal pyramidal neurons via the suppressed expression of BDNF gene $[53,54]$. BDNF constitutes a potent activator of neuronal mTOR [51] and, therefore, also rDNA transcriptional activity. Thus our current results correspond with previous molecular studies, which revealed decreased BDNF levels (for a review see: [55]) and mTOR signaling [56] in the suicidal PFC. Moreover, the disturbed serotonergic system morphology in suicide observed by us $[5,6,10]$ and other researchers [57] (for a review see: [58]) may be also related to BDNF hypofunction [59] (for reviews see: [60, 61]).

Previous neuropathological research by our workgroup [29] and others [30] suggested an increased microglial reaction in prefrontal regions as a diagnosis-overreaching phenomenon specific for suicide. The increased levels of pro-inflammatory cytokines found in prefrontal regions and cerebrospinal fluid of suicide victims suggested the devastating neurodegenerative role of microglia activation in suicide [62]. As revealed by experimental studies, activated microglia may induce oxidative stress in target neurons [31]. Besides microglia, oxidative stress in pyramidal neurons may be induced by 5HT2A serotonergic receptors (5HT2ARs) [63], which are up-regulated in the PFC of suicidal patients [64] (for reviews see: [43]). Therefore, both microglia activation and 5HT2ARs upregulation in the $\mathrm{PFC}$ may contribute to the decreased rDNA transcription in pyramidal neurons in suicide in a mTOR-dependent manner by the oxidative stress-induced protein REDD1, which is a potent mTOR inhibitor [47, 65].

Alternatively, human postmortem data suggest that the decreased rDNA transcription in PFC pyramidal neurons may be also a consequence of the hypermethylation of rDNA promoter region independently on mTOR pathway $[28,66$, 67]. On the other hand, the hypermethylation of BDNF promoter was revealed in the neocortex of suicide victims [67, 68]. Therefore, the epigenetic phenomena might hypothetically influence the rDNA transcription in pyramidal neurons in both direct and indirect manner.

Multiple upstream factors lead to attenuated rDNA transcription and disturbed plasticity of prefrontal pyramidal neurons is a far-reaching deleterious consequence of this devastating molecular phenomenon [25]. Therefore, our current results are in line with previous neuropathological study, which observed a decrease in pyramidal dendrites in the PFC of depressed suicide victims [69]. Since the arborisation of the pyramidal dendritic tree is a fundamental morphological signature of neuronal plasticity crucial for PFC function, the activation of diminished rDNA transcription targeted specifically in PFC pyramidal neurons may constitute new therapeutic avenue in future suicide prevention.

\section{Limitations}

The present study has certain limitations that have to be considered: (1) A relatively small number of predominantly male cases have been analyzed. Therefore, results have to be confirmed in a larger sample with more numerous female subjects. (2) The psychiatric diagnoses (also according to substance use disorders) and the data on possible psychotropic medication preceding death were not available. The levels of psychotropic drugs were established only in eight suicide victims where medication overdose constituted a cause of death. However, our current study did not aim at the relation between suicide and other mental disorders and our previous studies did not suggest that the decreased AgNOR area in prefrontal pyramidal neurons may be related to the medication in the last 3 months of life $[13,15]$. (3) The application of paraffin-embedded tissue is a limitation of our method compared to frozen brain samples, which would allow the application of a wider set of approaches. 


\section{Conclusion}

In summary, our results suggest the decreased rDNA transcription in pyramidal PFC neurons in suicide victims as a presumable consequence of multiple molecular events. The present method could not probably aid forensic differentiation diagnostics between suicidal and non-suicidal death in cases where traditional methods are inconclusive. However, further research is warranted to appropriately evaluate this issue.

Acknowledgements The research was supported by the Polish Ministry of Science and Higher Education. The authors would like to thank J. Pracka for her excellenttechnical assistance.

\section{Compliance with ethical standards}

Conflict of interest On behalf of all authors, the corresponding author states that there is no conflict of interest.

Open Access This article is distributed under the terms of the Creative Commons Attribution 4.0 International License (http://creativeco mmons.org/licenses/by/4.0/), which permits unrestricted use, distribution, and reproduction in any medium, provided you give appropriate credit to the original author(s) and the source, provide a link to the Creative Commons license, and indicate if changes were made.

\section{References}

1. van Heeringen K, Mann JJ (2014) The neurobiology of suicide. Lancet Psychiatry 1:63-72

2. Turecki G, Brent DA (2016) Suicide and suicidal behaviour. Lancet 387:1227-1239

3. American Psychiatric Association (2013) Diagnostic and statistical manual of mental disorders, 5th edn. American Psychiatric Publishing, Arlington

4. Brisch R, Steiner J, Mawrin C, Krzyżanowska M, Jankowski Z, Gos T (2017) Microglia in the dorsal raphe nucleus plays a potential role in both suicide facilitation and prevention in affective disorders. Eur Arch Psychiatry Clin Neurosci 267:403-415

5. Krzyżanowska M, Steiner J, Brisch R, Mawrin C, Busse S, Karnecki K, Jankowski Z, Gos T (2016) Decreased ribosomal DNA transcription in dorsal raphe nucleus neurons is specific for suicide regardless of psychiatric diagnosis. Psychiatry Res 241:43-46

6. Krzyżanowska M, Steiner J, Karnecki K, Kaliszan M, Brisch R, Wiergowski M, Braun K, Jankowski Z, Gos T (2016) Decreased ribosomal DNA transcription in dorsal raphe nucleus neurons differentiates between suicidal and non-suicidal death. Eur Arch Psychiatry Clin Neurosci 266:217-224

7. Gos T, Steiner J, Jankowski Z, Bogerts B (2013) Postmortemassessed impairment of neuronal activity in depression: the dominantimpact of suicide.CNS Neurol. Disord Drug Targets 12:930-935

8. Mennel HD, Müller I (1994) Morphometric investigation on nuclear and nucleolar arrangement and AgNOR content in the rat hippocampus under normal and ischemic conditions. Exp Toxicol Pathol 46:491-501

9. Bielau H, Mawrin C, Krell D, Agelink MW, Trübner K, Davis R, Gos T, Bogerts B, Bernstein HG, Baumann B (2005) Differences in activation of the dorsal raphe nucleus depending on performance of suicide. Brain Res 1039:43-52

10. Gos T, Krell D, Brisch R, Bielau H, Trübner K, Steiner J, Bernstein HG, Bogerts B (2008) Demonstration of decreased activity of dorsal raphe nucleus neurons in depressed suicidal patients by the AgNOR staining method. J Affect Disord 111:251-260

11. Derenzini M (2000) The AgNORs. Micron 31:117-120

12. García-Moreno LM, Cimadevilla JM, González Pardo H, Zahonero MC, Arias JL (1997) NOR activity in hippocampal areas during the postnatal development and ageing. Mech Ageing Dev 97:173-181

13. Gos T, Krell D, Brisch R, Bielau H, Trübner K, Bernstein HG, Bogerts B (2007) The changes of AgNOR parameters of anterior cingulate pyramidal neurons are region-specific in suicidal and non-suicidal depressive patients. World J Biol Psychiatry $8: 245-255$

14. Gos T, Krell D, Brisch R, Bielau H, Trübner K, Bernstein HG, Bogerts B (2007) The changes in AgNOR parameters of dorsal raphe nucleus neurons are related to suicide. Leg Med (Tokyo) 9:251-257

15. Gos T, Krell D, Bielau H, Steiner J, Mawrin C, Trübner K, Brisch R, Bernstein HG, Jankowski Z, Bogerts B (2009) Demonstration of disturbed activity of orbitofrontal pyramidal neurons in depressed patients by the AgNOR staining method. J Affect Disord 118:131-138

16. Gos T, Krell D, Bielau H, Steiner J, Trübner K, Brisch R, Bernstein HG, Jankowski Z, Bogerts B (2009) Demonstration of disturbed activity of external globus pallidus projecting neurons in depressed patients by the AgNOR staining method. J Affect Disord 119:149-155

17. Gos T, Krell D, Bielau H, Steiner J, Mawrin C, Trübner K, Brisch R, Bernstein HG, Jankowski Z, Bogerts B (2010) Demonstration of disturbed activity of the lateral amygdaloid nucleus projection neurons in depressed patients by the AgNOR staining method. J Affect Disord 126:402-410

18. Hayashida M, Miyaoka T, Tsuchie K, Yasuda H, Wake R, Nishida A, Inagaki T, Toga T, Nagami H, Oda T, Horiguchi J (2009) Hyperbilirubinemia-related behavioral and neuropathological changes in rats: a possible schizophrenia animal model. Prog Neuropsychopharmacol Biol Psychiatry 33:581-588

19. Ploton D, Menager M, Jeannesson P, Himber G, Pigeon F, Adnet JJ (1986) Improvement in the staining and in the visualization of the argyrophilic proteins of the nucleolar organizer region at the optical level. Histochem J 18:5-14

20. Ploton D, Visseaux-Coletto B, Canellas JC, Bourzat C, Adnet JJ, Lechki C, Bonnet N (1992) Semiautomatic quantification of silver-stained nucleolar organizer regions in tissue sections and cellular smears. Anal Quant Cytol Histol 14:14-23

21. Ploton D (1994) Structure and molecular organization of the nucleolus. Zentralbl Pathol 140:3-6

22. Rüschoff J, Elsässer HP, Adler G (1995) Correlation of nucleolar organizer regions with secretory and regenerative process in experimental cerulein-induced pancreatitis in the rat. Pancreas 11:154-159

23. Raska I, Shaw PJ, Cmarko D (2006) New insights into nucleolar architecture and activity. Int Rev Cytol 255:177-235

24. Sirri V, Urcuqui-Inchima S, Roussel P, Hernandez-Verdun D (2008) Nucleolus: the fascinating nuclear body. Histochem Cell Biol 129:13-31

25. Gomes C, Smith SC, Youssef MN, Zheng JJ, Hagg T, Hetman M (2011) RNA polymerase 1-driven transcription as a mediator of BDNF-induced neurite outgrowth. J Biol Chem 286:4357-4363

26. Slomnicki LP, Pietrzak M, Vashishta A, Jones J, Lynch N, Elliot S, Poulos E, Malicote D, Morris BE, Hallgren J, Hetman M (2016) Requirement of neuronal ribosome synthesis for growth and maintenance of the dendritic tree. J Biol Chem 291:5721-5739 
27. Vashishta A, Slomnicki LP, Pietrzak M, Smith SC, Kolikonda M, Naik SP, Parlato R, Hetman M (2018) RNA polymerase 1 is transiently regulated by seizures and plays a role in a pharmacological kindling model of epilepsy. Mol Neurobiol 55:8374-8387

28. McGowan PO, Szyf M (2010) The epigenetics of social adversity in early life: implications for mental health outcomes. Neurobiol Dis 39:66-72

29. Steiner J, Bielau H, Brisch R, Danos P, Ullrich O, Mawrin C, Bernstein HG, Bogerts B (2008) Immunological aspects in the neurobiology of suicide: elevated microglial density in schizophrenia and depression is associated with suicide. J Psychiatr Res 42:151-157

30. Schnieder TP, Trencevska I, Rosoklija G, Stankov A, Mann JJ, Smiley J, Dwork AJ (2014) Microglia of prefrontal white matter in suicide. J Neuropathol Exp Neurol 73:880-890

31. Chen SH, Oyarzabal EA, Hong JS (2016) Critical role of the Mac1/NOX2 pathway in mediating reactive microgliosis-generated chronic neuroinflammation and progressive neurodegeneration. Curr Opin Pharmacol 26:54-60

32. Mayer C, Bierhoff H, Grummt I (2005) The nucleolus as a stress sensor: JNK2 inactivates the transcription factor TIF-IA and down-regulates rRNA synthesis. Genes Dev 19:933-941

33. Steiner J, Mawrin C, Ziegeler A, Bielau H, Ullrich O, Bernstein HG, Bogerts B (2006) Distribution of HLA-DR-positive microglia in schizophrenia reflects impaired cerebral lateralization. Acta Neuropathol 112:305-316

34. Polak M, Haymaker W, Johnson JE et al (1982) Neuroglia and their reactions. In: Haymaker W, Adams RD (eds) Histology and histopathology of nervous system. Charles C. Thomas Publishing, Springfield, pp 363-480

35. Hyer MM, Phillips LL, Neigh GN (2018) Sex differences in synaptic plasticity: hormones and beyond. Front Mol Neurosci 11:266

36. Labonté B, Engmann O, Purushothaman I, Menard C, Wang J, Tan C, Scarpa JR, Moy G, Loh YE, Cahill M, Lorsch ZS, Hamilton PJ, Calipari ES, Hodes GE, Issler O, Kronman H, Pfau M, Obradovic ALJ, Dong Y, Neve RL, Russo S, Kasarskis A, Tamminga C, Mechawar N, Turecki G, Zhang B, Shen L, Nestler EJ (2017) Sex-specific transcriptional signatures in human depression. Nat Med 23:1102-1111

37. Price JL, Drevets WC (2010) Neurocircuitry of mood disorders. Neuropsychopharmacology 35:192-216

38. Bush G, Luu P, Posner MI (2000) Cognitive and emotional influences in anterior cingulate cortex. Trends Cogn Sci 4:215-222

39. Steiner J, Walter M, Gos T, Guillemin GJ, Bernstein HG, Sarnyai Z, Mawrin C, Brisch R, Bielau H, Meyer zu Schwabedissen L, Bogerts B, Myint AM (2011) Severe depression is associated with increased microglial quinolinic acid in subregions of the anterior cingulate gyrus: evidence for an immune-modulated glutamatergic neurotransmission? J Neuroinflammation 8:94

40. Perlis RH (2011) Translating biomarkers to clinical practice. Mol Psychiatry 16:1076-1087

41. Neumüller RA, Gross T, Samsonova AA, Vinayagam A, Buckner M, Founk K, Hu Y, Sharifpoor S, Rosebrock AP, Andrews B, Winston F, Perrimon N (2013) Conserved regulators of nucleolar size revealed by global phenotypic analyses. Sci Signal 6:70

42. Mayer C, Grummt I (2006) Ribosome biogenesis and cell growth: mTOR coordinates transcription by all three classes of nuclear RNA polymerases. Oncogene 25:6384-6391

43. Pandey GN (2013) Biological basis of suicide and suicidal behavior. Bipolar Disord 15:524-541

44. Pandey GN, Rizavi HS, Zhang H, Bhaumik R, Ren X (2016) The expression of the suicide-associated gene SKA2 is decreased in the prefrontal cortex of suicide victims but not of nonsuicidal patients. Int J Neuropsychopharmacol 19
45. Shoji Y, Osman W, Zilliacus J (2007) Polyamine-modulated factor 1 represses glucocorticoid receptor activity. Biochem Biophys Res Commun 361:176-181

46. Chen GG, Fiori LM, Moquin L, Gratton A, Mamer O, Mechawar N, Turecki G (2010) Evidence of altered polyamine concentrations in cerebral cortex of suicide completers. Neuropsychopharmacology 35:1477-1484

47. Polman JA, Hunter RG, Speksnijder N, van den Oever JM, Korobko OB, McEwen BS, de Kloet ER, Datson NA (2012) Glucocorticoids modulate the mTOR pathway in the hippocampus: differential effects depending on stress history. Endocrinology 153:4317-4327

48. Sequeira A, Mamdani F, Ernst C, Vawter MP, Bunney WE, Lebel V, Rehal S, Klempan T, Gratton A, Benkelfat C, Rouleau GA, Mechawar N, Turecki G (2009) Global brain gene expression analysis links glutamatergic and GABAergic alterations to suicide and major depression. PLoS One 4:e6585

49. Dean B, Gibbons AS, Boer S, Uezato A, Meador-Woodruff J, Scarr E, McCullumsmith RE (2016) Changes in cortical $\mathrm{N}$-methyl-D-aspartate receptors and post-synaptic density protein 95 in schizophrenia, mood disorders and suicide. Aust N Z J Psychiatry 50:275-283

50. Zhao J, Verwer RWH, Gao SF, Qi XR, Lucassen PJ, Kessels HW, Swaab DF (2018) Prefrontal alterations in GABAergic and glutamatergic gene expression in relation to depression and suicide. $\mathrm{J}$ Psychiatr Res 102:261-274

51. Ignácio ZM, Réus GZ, Arent CO, Abelaira HM, Pitcher MR, Quevedo J (2016) New perspectives on the involvement of mTOR in depression as well as in the action of antidepressant drugs. $\mathrm{Br}$ J Clin Pharmacol 82:1280-1290

52. Gos T, Günther K, Bielau H, Dobrowolny H, Mawrin C, Trübner K, Brisch R, Steiner J, Bernstein HG, Jankowski Z, Bogerts B (2009) Suicide and depression in the quantitative analysis of glutamic acid decarboxylase-immunoreactive neuropil. J Affect Disord 113:45-55

53. Berninger B, Marty S, Zafra F, da Penha Berzaghi M, Thoenen $\mathrm{H}$, Lindholm D (1995) GABAergic stimulation switches from enhancing to repressing BDNF expression in rat hippocampal neurons during maturation in vitro. Development 121:2327-2335

54. Zafra F, Castrén E, Thoenen H, Lindholm D (1991) Interplay between glutamate and gamma-aminobutyric acid transmitter systems in the physiological regulation of brain-derived neurotrophic factor and nerve growth factor synthesis in hippocampal neurons. Proc Natl Acad Sci U S A 88:10037-10041

55. Dwivedi Y (2012) Brain-derived neurotrophic factor in suicide pathophysiology. In: Dwivedi Y (ed) The Neurobiological basis of suicide. CRC Press, New York, pp 139-158

56. Jernigan CS, Goswami DB, Austin MC, Iyo AH, Chandran A, Stockmeier CA, Karolewicz B (2011) The mTOR signaling pathway in the prefrontal cortex is compromised in major depressive disorder. Prog Neuropsychopharmacol Biol Psychiatry 35:1774-1779

57. Underwood MD, Kassir SA, Bakalian MJ, Galfalvy H, Mann JJ, Arango V (2012) Neuron density and serotonin receptor binding in prefrontal cortex in suicide. Int J Neuropsychopharmacol $15: 435-447$

58. Bach H, Arango V (2012) Neuroanatomy of serotonergic abnormalities in suicide. In: Dwivedi Y (ed) The neurobiological basis of suicide. CRC Press, New York, pp 11-27

59. Rumajogee P, Madeira A, Vergé D, Hamon M, Miquel MC (2002) Up-regulation of the neuronal serotoninergic phenotype in vitro: BDNF and camp share TRK b-dependent mechanisms. J Neurochem 83:1525-1528

60. Homberg JR, Molteni R, Calabrese F, Riva MA (2014) The serotonin-BDNF duo: developmental implications for the vulnerability to psychopathology. Neurosci Biobehav Rev 43:35-47 
61. Popova NK, Ilchibaeva TV, Naumenko VS (2017) Neurotrophic factors (BDNF and GDNF) and the serotonergic system of the brain. Biochemistry 82:308-317

62. Brundin L, Erhardt S, Bryleva EY, Achtyes ED, Postolache TT (2015) The role of inflammation in suicidal behaviour. Acta Psychiatr Scand 132:192-203

63. Capela JP, Fernandes E, Remião F, Bastos ML, Meisel A, Carvalho F (2007) Ecstasy induces apoptosis via 5-HT(2A)-receptor stimulation in cortical neurons. Neurotoxicology 28:868-875

64. Oquendo MA, Russo SA, Underwood MD, Kassir SA, Ellis SP, Mann JJ, Arango V (2006) Higher postmortem prefrontal 5-HT2A receptor binding correlates with lifetime aggression in suicide. Biol Psychiatry 59:235-243

65. Choi HS, Ahn JH, Park JH, Won MH, Lee CH (2016) Agedependent changes in the protein expression levels of Redd 1 and mTOR in the gerbil hippocampus during normal aging. Mol Med Rep 13:2409-2414
66. Haghighi F, Xin Y, Chanrion B, O’Donnell AH, Ge Y, Dwork AJ, Arango V, Mann JJ (2014) Increased DNA methylation in the suicide brain. Dialogues Clin Neurosci 16:430-438

67. Schneider E, El Hajj N, Müller F, Navarro B, Haaf T (2015) Epigenetic dysregulation in the prefrontal cortex of suicide completers. Cytogenet Genome Res 146:19-27

68. Keller S, Sarchiapone M, Zarrilli F, Videtic A, Ferraro A, Carli V, Sacchetti S, Lembo F, Angiolillo A, Jovanovic N, Pisanti F, Tomaiuolo R, Monticelli A, Balazic J, Roy A, Marusic A, Cocozza S, Fusco A, Bruni CB, Castaldo G, Chiariotti L (2010) Increased BDNF promoter methylation in the Wernicke area of suicide subjects. Arch Gen Psychiatry 67:258-267

69. Hercher C, Canetti L, Turecki G, Mechawar N (2010) Anterior cingulate pyramidal neurons display altered dendritic branching in depressed suicides. J Psychiatr Res 44:286-293 